\title{
The assessment of GWAS - identified polymorphisms associated with infertility risk in Polish women with endometriosis
}

\author{
Maciej Osiński ${ }^{1}$, Adrianna Mostowska ${ }^{2}$, Przemysław Wirstlein ${ }^{1}$, Ewa Wender-Ożegowska ${ }^{1}$, \\ Paweł Piotr Jagodziński², Małgorzata Szczepańska² \\ ${ }^{1}$ Department of Obstetrics, Gynecology and Gynecological Oncology, Division of Reproduction, \\ University of Medical Sciences Karol Marcinkowski, Poznań, Poland \\ ${ }^{2}$ Department of Biochemistry and Molecular Biology, University of Medical Sciences Karol Marcinkowski, Poznań, Poland
}

\begin{abstract}
Objectives: Genome-wide association studies in patients with endometriosis revealed ten significant single nucleotide polymorphisms (SNPs) in the Caucasian population, which include rs12700667 near NFE2L3, rs12037376 in WNT4, rs7521902 near WNT4, rs13394619 in GREB1, rs10859871 near VEZT, rs1537377 near CDKN2B-AS1, rs4141819 near ETAA1, rs7739264 near ID4, rs1519761 near RND3 and rs6542095 near IL1A.

Material and methods: We replicated ten polymorphisms among infertile women with endometriosis $(n=315)$ and healthy fertile women $(n=406)$ in the Polish Caucasian population. Genotyping was conducted either by high-resolution melting curve analysis or by a pre-designed TaqMan probe.

Results: For all infertile women with endometriosis, the $p$ values of the Cochran-Armitage trend test for the rs 12700667 SNP was $p_{\text {trend }}=0.038$ and the odds ratio (OR) for the risk allele frequency (RAF) of rs 12700667 was $1.304(95 \% \mathrm{Cl}=1.009-1.685$; $p=0.042$ ). In patients with endometriosis with severity stages III/IV, $p_{\text {trend }}$ for rs 12700667 SNP was 0.036 and OR for the RAF was $1.394(95 \% \mathrm{Cl}=1.010-1.923 ; \mathrm{p}=0.043)$. In infertile women with endometriosis with severity stages III/IV for rs4141819 SNP, we observed $p_{\text {trend }}=0.026$ and for RAF the $O R=1.350(95 \% \mathrm{Cl}=1.032-1.766 ; p=0.029)$.

Conclusions: Our results demonstrate association of RAF of rs12700667 and rs4141819 SNPs with infertility in Polish women with advanced endometriosis.
\end{abstract}

Key words: GWAS, endometriosis, infertility

Ginekologia Polska 2018; 89, 6: 304-310

\section{INTRODUCTION}

Endometriosis is a complex gynaecological health problem in women, which is characterized by the aberrant presence of endometrial cells outside the uterus [1]. This benign disease is usually limited to the pelvis and is characterized by peritoneal inflammation, neovascularization, fibrosis, and ovarian cysts [1]. The morbidity for endometriosis ranges from $5-10 \%$ and is accompanied by subfertility in women at reproductive age [2,3]. Despite the extensive conducted studies, the aetiology of endometriosis is still unclear. The presence of endometrial tissue and cells in the peritoneal cavity has been explained by the standard theory of retrograde menstruation along the fallopian tubes [4]. Although retrograde menstruation is observed in $90 \%$ of women, merely $10-20 \%$ of women suffer from endometriosis, which suggests the involvement of different genetic and environmental components in etiopathogenesis [5, 6]. Recently, the genetic and epigenetic background of endometriosis has been demonstrated [5]. The aetiology of endometriosis may be related to genetic factors, which increases oestrogen activity, the production of prostaglandins, cytokines, and metalloproteinases, as well as enhances of oncogenic 
Table 1. Characteristics of SNPs genotyped in the data set

\begin{tabular}{|c|c|c|c|c|c|}
\hline SNP & Locus & Location (bp) $^{\mathrm{a}}$ & Alleles $^{b}$ & SNP location & Gene $^{c}$ \\
\hline rs12700667 & $7 \mathrm{p} 15.2$ & 25901639 & $A / \underline{G}$ & intergenic & NPVF / NFE2L3 \\
\hline rs12037376 & $1 p 36.12$ & 22462111 & $\underline{A} / \mathrm{G}$ & intronic & WNT4 \\
\hline rs7521902 & $1 p 36.12$ & 22490724 & $\underline{\mathbf{A}} / \mathrm{C}$ & intergenic & WNT4 / ZBTB40 \\
\hline rs13394619 & $2 p 25.1$ & 11727507 & $\underline{A} / \mathrm{G}$ & intronic (function: splice-3) & GREB1 \\
\hline rs10859871 & $12 q 22$ & 95711876 & $\mathrm{~A} / \underline{\mathrm{C}}$ & intergenic & VEZT / METAP2 \\
\hline rs1537377 & $9 p 21.3$ & 22169700 & $\underline{C} / \mathrm{T}$ & intergenic & CDKN2B / DMRTA1 \\
\hline rs4141819 & $2 \mathrm{p} 14$ & 67864675 & $\underline{c} / \mathrm{T}$ & intergenic & ETAA1 / C1D \\
\hline rs7739264 & $6 \mathrm{p} 22.3$ & 19785588 & $\underline{\mathbf{C}} / \mathrm{T}$ & intergenic & RNF144B / ID4 \\
\hline rs1519761 & $2 q 23.3$ & 151633204 & $\mathrm{~A} / \underline{\mathbf{G}}$ & intergenic & RND3 / RBM43 \\
\hline rs6542095 & $2 q 13$ & 113529183 & $\underline{\mathbf{C}} / \mathrm{T}$ & intergenic & CKAP2L / IL1A \\
\hline
\end{tabular}

a - NCBI build 37 / hg19; ${ }^{\text {b }}$ - underline denotes the minor allele; ${ }^{\mathrm{c}}$ - genes separated by forward slash indicate nearest protein coding genes upstream / downstream of the SNP

pathways [5]. To date, five genome-wide association studies (GWAS) have been conducted on four independent groups, encompassing women with endometriosis [7-13]. These GWAS analyses have revealed ten genome-wide significant loci in Caucasians, presented in Table 1 [7-13]. Despite finding several genome-wide significant loci linked to endometriosis, there is still a need for confirmation in different populations.

We aimed to assess the rs12700667, rs12037376, rs7521902, rs13394619, rs10859871, rs1537377, rs4141819, rs7739264, rs1519761 and rs6542095 SNPs genome-wide significant loci (Tab. 1) as possible infertility risk in Polish women with endometriosis.

\section{MATERIAL AND METHODS}

\section{A case-control study}

A case-control study design was used in 315 patients with endometriosis and 406 matched controls (Tab. 2). Peripheral blood samples were randomly obtained between November 2014 and December 2017 from infertile women with endometriosis and control women of similar ages from the Gynaecologic and Obstetrical University Hospital, Division of Reproduction at Poznan University of Medical Sciences, Poland (Tab. 1). After informed consent was obtained, approximately $7 \mathrm{~mL}$ venous blood was drawn and collected into the Vacutainer System with EDTA (Sarstedt, Germany) and stored at $-20^{\circ} \mathrm{C}$ until DNA isolation was performed.

The patients with infertility and endometriosis underwent laparoscopy and had a histologically confirmed diagnosis at the Gynaecologic and Obstetrical University Hospital, Division of Reproduction at Poznan University of Medical Sciences, Poland. Patients with endometriosis were divided into two subgroups according to the revised American Society for Reproductive Medicine (rASRM) classification system [14]; $\mathrm{n}=142$ patients had minimal or mild endometriosis (stages I-II), $\mathrm{n}=166$ had moderate or severe endometriosis (stages III-IV), and $\mathrm{n}=7$ patients had an undefined stage of endometriosis (Tab. 2). The control group was comprised of healthy women $(n=406)$, without history of infertility, who had a caesarean section performed (Tab. 2).

The inclusion and exclusion criteria for the infertile women with endometriosis and the women without disease were previously described [15]. The inclusion criteria for infertile women diagnosed with endometriosis were as follows: regular menses, no anatomical changes in the reproductive tract, no hormonal treatments, and a minimum of one year of infertility with a current desire for conception. The exclusion criteria were as follows: mechanical distortion of the endometrial cavity by fibroids, bilateral tubal occlusion, male factor infertility, adenomyosis, polycystic ovary syndrome (PCOS) and benign or malignant gynaecological diseases. The inclusion criteria for fertile control women were as follows: performed caesarean section, regular menses, no anatomical changes in the reproductive tract, no hormonal treatments, and at least one child born no more than one year before the study (Tab. 2). The exclusion criteria were as follows: signs of past or present inflammation, pelvic abnormalities, endometriosis, adenomyosis, PCOS or any other benign or malignant gynaecological diseases, which was confirmed during surgical exploration. Both patients with endometriosis and healthy controls were all Caucasians of Polish ancestry (Tab. 2).

\section{Ethical approval}

All procedures performed in this study which involved human participants were in accordance with the ethical standards of the ethics committee of Poznan University of Medical Sciences and with the 1964 Helsinki declaration and its ethical standards. Informed consent was obtained from all individual participants included in the study. 


\begin{tabular}{l|c|c|}
\hline \multicolumn{3}{|l|}{ Table 2. Characteristics of the populations of infertile women with } \\
endometriosis
\end{tabular}

a - median (range); ${ }^{b}$ — revised American Society for Reproductive Medicine (rASRM) [14]; NA — not applicable

\section{Genotyping of rs12700667, rs12037376, rs7521902, rs13394619, rs10859871, rs1537377, rs4141819, rs7739264, rs1519761 and rs6542095 SNPs}

Genomic DNA was isolated from peripheral blood leukocytes by salt extraction. The SNPs evaluated in this study were selected based on GWAS and meta-analyses studies [8, 9, 11-13]. Genotyping of rs12700667, rs12037376, rs7521902, rs13394619, rs10859871, rs1537377, rs4141819, rs7739264, and rs1519761 variants was carried out by high resolution melting curve analysis (HRM) on the LightCycler 96 system (Roche Diagnostics, Mannheim, Germany) with the use of 5x HOT FIREPol EvaGreen HRM Mix (Solis BioDyne, Tartu, Estonia). The PCR programme consisted of an initial step at $95^{\circ} \mathrm{C}$ for 15 minutes to activate HOT FIREPol DNA polymerase, followed by 50 amplification cycles of denaturation at $95^{\circ} \mathrm{C}$ for 10 seconds, primer-dependent annealing (Tab. 3) for 10 seconds, and elongation at $72^{\circ} \mathrm{C}$ for $15 \mathrm{sec}-$ onds. Amplified DNA fragments were then subjected to HRM with $0.1^{\circ} \mathrm{C}$ increments in temperatures ranging from 65 to $95^{\circ} \mathrm{C}$ (Tab. 3). The final concentrations of reagents in HRM reactions were as follows: 1x HOT FIREPol EvaGreen HRM Mix, $0.2 \mathrm{pmol} / \mu \mathrm{L}$ of each primer and $2 \mathrm{ng} / \mu \mathrm{L}$ DNA template. The HRM reactions were performed in a $10 \mu \mathrm{L}$ volume. Genotyping of rs6542095 was carried out on the LightCycler 480 system (Roche Diagnostics, Mannheim, Germany) using pre-designed TaqMan SNP, according to the manufacturer's instructions provided by Applied Biosystems (Applied Biosystems, Foster City, CA, USA) (Tab. 3).

\section{Data analysis}

Hardy-Weinberg equilibrium (HWE) was assessed by Pearson's goodness-of-fit Chi-square $\left(\mathrm{X}^{2}\right)$ statistic. The SNPs were studied for associations with endometriosis using the

Table 3. Primers and HRM conditions for replication genotyping

\begin{tabular}{|c|c|c|c|c|c|}
\hline rs no. & Alleles & $\begin{array}{l}\text { Primers for PCR amplification } \\
\qquad\left(5^{\prime}-3^{\prime}\right)\end{array}$ & $\begin{array}{l}\text { PCR product } \\
\text { length (bp) }\end{array}$ & $\begin{array}{l}\text { Annealing } \\
\text { temp. }\left({ }^{\circ} \mathrm{C}\right)\end{array}$ & $\begin{array}{l}\text { Melt. temp. } \\
\text { range }\left({ }^{\circ} \mathrm{C}\right)\end{array}$ \\
\hline \multirow{2}{*}{ rs12700667 } & \multirow{2}{*}{$A / G$} & F: GAGAGTGAAAATGTGACAAAAGTGA & \multirow{2}{*}{90} & \multirow{2}{*}{55} & \multirow{2}{*}{$74-89$} \\
\hline & & R: AAGCGCCACACCATATACATC & & & \\
\hline \multirow{2}{*}{ rs12037376 } & \multirow{2}{*}{$A / G$} & F: GAGACCACAGGCTTCCATA & \multirow{2}{*}{78} & \multirow{2}{*}{55} & \multirow{2}{*}{$78-93$} \\
\hline & & R:TTCAGGAGTAAGGGGTGCT & & & \\
\hline \multirow{2}{*}{ rs7521902 } & \multirow{2}{*}{$\mathrm{A} / \mathrm{C}$} & F: GCTCTGTCTTCGAGGCACTT & \multirow{2}{*}{104} & \multirow{2}{*}{53} & \multirow{2}{*}{$80-95$} \\
\hline & & R:TCCCAATTACATGATCCTCTCC & & & \\
\hline \multirow{2}{*}{ rs13394619 } & \multirow{2}{*}{$A / G$} & F: СCCCTTGTCACTTCTCTGTC & \multirow{2}{*}{119} & \multirow{2}{*}{55} & \multirow{2}{*}{$75-90$} \\
\hline & & R:TACCATTTGGGTAGCACCA & & & \\
\hline \multirow{2}{*}{ rs10859871 } & \multirow{2}{*}{$\mathrm{A} / \mathrm{C}$} & F: CAAGTGGGCAATTTATTTCTCTG & \multirow{2}{*}{144} & \multirow{2}{*}{58} & \multirow{2}{*}{$74-89$} \\
\hline & & R: TGCAATAGGATTCTCACATTAACCT & & & \\
\hline \multirow{2}{*}{ rs1537377 } & \multirow{2}{*}{$\mathrm{C} / \mathrm{T}$} & F: CAGCTCTACTCTTGGATTTGG & \multirow{2}{*}{110} & \multirow{2}{*}{55} & \multirow{2}{*}{$72-87$} \\
\hline & & R: ATGCATAACAGTCTATAAGTAGG & & & \\
\hline \multirow{2}{*}{ rs4141819 } & \multirow{2}{*}{$\mathrm{C} / \mathrm{T}$} & F: CCTCAGGTGAAAGTTCATGC & \multirow{2}{*}{85} & \multirow{2}{*}{55} & \multirow{2}{*}{$75-90$} \\
\hline & & R:TGAGGAAAGTGGCTAGAGGA & & & \\
\hline \multirow{2}{*}{ rs7739264 } & \multirow{2}{*}{$\mathrm{C} / \mathrm{T}$} & F: GAGGCCACTCACTACAATGC & & $5 ?$ & \\
\hline & & R: CCTCTTGGACAGATTTTCCTG & וכנו & ככ & $13-90$ \\
\hline 1076 & 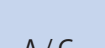 & F: CAAAAATATGTTGTATATGAG & 01 & $52+>$ & 65.80 \\
\hline TS1519/01 & A/ G & R:TAATCCATGTTTTCCTAC & 91 & 53 & $65-80$ \\
\hline
\end{tabular}

Genotyping of rs6542095 was carried out on the LightCycler 480 system (Roche Diagnostics, Mannheim, Germany) using pre-designed TaqMan SNP Genotyping Assay according to the manufacturer's instructions provided by Applied Biosystems (Applied Biosystems, Foster City, CA) 
Cochran-Armitage trend test. Differences in the risk allele frequencies (RAF) between the cases and controls were calculated using $x^{2}$ analysis. The odds ratio (OR) and $95 \%$ confidence intervals $(95 \% \mathrm{Cl})$ were also calculated. The statistical analyses were conducted with Statistica version 10 (2011, Stat Soft, Inc., Tulsa, USA).

\section{RESULTS}

The comparison of rs12700667, rs12037376, rs7521902, rs13394619 rs10859871, rs1537377, rs4141819, rs7739264, rs1519761 and rs6542095 genotypes and allele frequencies between all infertile women with endometriosis and fertile healthy women

There was no divergence from the HWE in the frequency of genotypes between all infertile women with endometriosis and the fertile women groups (Tab. 4). The prevalence of the genotype and allele frequencies, OR and $95 \% \mathrm{Cl}$ calculated for the ten SNPs are presented in
Table 4. The statistical significance of the $p$ values of the Cochran-Armitage trend test $\left(p_{\text {trend }}=0.038\right.$ ) was found for the rs12700667 SNP and the OR for RAF was 1.304 (95\% $\mathrm{Cl}=1.009-1.685 ; \mathrm{p}=0.042)$. However, none of the SNPs, rs12037376, rs7521902, rs13394619, rs10859871, rs1537377, rs4141819, rs7739264, rs1519761 or rs6542095 displayed a significant association with all infertile women with endometriosis in the additive inheritance model (Tab. 4).

The comparison of rs12700667, rs12037376, rs7521902, rs13394619, rs10859871, rs1537377, rs4141819, rs7739264, rs1519761 and rs6542095 genotypes and allele frequencies between infertile women with endometriosis in stages III and IV and fertile healthy women

We found divergence from the HWE in the frequency of genotypes in the subgroup with endometriosis with severity stage I/II for rs1519761 but no divergence was observed from the HWE for other subgroups of women with

Table 4. Association between GWAS-identified polymorphisms and the risk of endometriosis

\begin{tabular}{|c|c|c|c|c|c|}
\hline SNP & Genotypes & RAF $^{\mathbf{a}}$ & $\mathbf{p}_{\text {trend }}$ & $\begin{array}{c}\text { OR }_{\text {allelic }}(95 \% \mathrm{CI})^{\mathrm{b}} \\
\text { p value }\end{array}$ & $H W^{d}$ \\
\hline rs12700667 & AA / AG / GG & $A-$ major & & & \\
\hline Controls & $229 / 154 / 19$ & 0.76 & & & 0.560 \\
\hline Cases & $201 / 101 / 10$ & 0.81 & 0.038 & $1,304(1,009-1,685) ; 0.042$ & 0.821 \\
\hline Cases stage I and II & $91 / 42$ / 7 & 0.80 & 0.178 & $1,255(0.898-1,754) ; 0.183$ & 0.761 \\
\hline Cases stage III and IV & $108 / 55 / 3$ & 0.82 & 0.036 & $1,394(1,010-1,923) ; 0.043$ & 0.403 \\
\hline rs12037376 & GG / AG / AA & A-minor & & & \\
\hline Controls & $285 / 112 / 8$ & 0.16 & & & 0.732 \\
\hline Cases & $211 / 89 / 11$ & 0.18 & 0.302 & $1,157(0.876-1,530) ; 0.304$ & 0.914 \\
\hline Cases stage I and II & $97 / 39$ / 5 & 0.17 & 0.533 & $1,121(0.781-1,608) ; 0.537$ & 0.909 \\
\hline Cases stage III and IV & $109 / 48 / 6$ & 0.18 & 0.281 & $1,202(0.857-1,685) ; 0.286$ & 0.969 \\
\hline rs7521902 & $\mathrm{CC} / \mathrm{AC} / \mathrm{AA}$ & A-minor & & & \\
\hline Controls & $218 / 155 / 24$ & 0.26 & & & 0.876 \\
\hline Cases & $159 / 133 / 18$ & 0.27 & 0.462 & $1,091(0.860-1,384) ; 0.474$ & 0.354 \\
\hline Cases stage I and II & $71 / 63 / 5$ & 0.26 & 0.814 & $1,037(0.760-1,415) ; 0.820$ & 0.133 \\
\hline Cases stage III and IV & $85 / 68 / 12$ & 0.28 & 0.417 & $1,125(0.843-1,502) ; 0.422$ & 0.950 \\
\hline rs13394619 & GG / AG / AA & A-minor & & & \\
\hline Controls & $126 / 184$ / 89 & 0.45 & & & 0.379 \\
\hline Cases & $96 / 154$ / 59 & 0.44 & 0.618 & $0.947(0.767-1,170) ; 0.612$ & 0.981 \\
\hline Cases stage I and II & 44 / 75 / 22 & 0.42 & 0.365 & $0.879(0.668-1,157) ; 0.358$ & 0.562 \\
\hline Cases stage III and IV & 52 / 74 / 37 & 0.45 & 0.992 & $1,001(0.773-1,297) ; 0.991$ & 0.561 \\
\hline rs10859871 & $\mathrm{AA} / \mathrm{AC} / \mathrm{CC}$ & $\mathrm{C}-$ minor & & & \\
\hline Controls & 197 / 166 / 42 & 0.31 & & & 0.728 \\
\hline Cases & $140 / 151 / 23$ & 0.31 & 0.835 & $1,024(0.818-1,282) ; 0.837$ & 0.117 \\
\hline Cases stage I and II & $69 / 65$ / 8 & 0.29 & 0.459 & $0.894(0.664-1,204) ; 0.460$ & 0.344 \\
\hline Cases stage III and IV & $67 / 85 / 13$ & 0.34 & 0.357 & $1,135(0.864-1,491) ; 0.362$ & 0.142 \\
\hline
\end{tabular}


Table 4 (cont.). Association between GWAS-identified polymorphisms and the risk of endometriosis

\begin{tabular}{|c|c|c|c|c|c|}
\hline SNP & Genotypes & $\mathbf{R A F}^{\mathbf{a}}$ & $\mathbf{p}_{\text {trend }}$ & $\begin{array}{l}\text { OR }_{\text {allelic }}(95 \% \mathrm{Cl})^{\mathrm{b}} ; \\
\text { p value }\end{array}$ & $H W^{d}$ \\
\hline rs1537377 & $\mathrm{TT} / \mathrm{CT} / \mathrm{CC}$ & $\mathrm{C}-$ minor & & & \\
\hline Controls & $144 / 198 / 58$ & 0.39 & & & 0.749 \\
\hline Cases & $101 / 165 / 45$ & 0.41 & 0.491 & $1,075(0.869-1,332) ; 0.505$ & 0.234 \\
\hline Cases stage I and II & $47 / 78 / 16$ & 0.39 & 0.941 & $0.990(0.750-1,307) ; 0.943$ & 0.155 \\
\hline Cases stage III and IV & $50 / 84 / 29$ & 0.44 & 0.173 & $1,194(0.920-1,551) ; 0.182$ & 0.828 \\
\hline rs4141819 & $\mathrm{TT} / \mathrm{CT} / \mathrm{CC}$ & C-minor & & & \\
\hline Controls & $195 / 171 / 38$ & 0.31 & & & 0.998 \\
\hline Cases & $124 / 151 / 31$ & 0.35 & 0.0856 & $1,212(0.9693-1,517) 0.0913$ & 0.311 \\
\hline Cases stage I and II & $64 / 64 / 13$ & 0.32 & 0.672 & $1,065(0.795-1,425) ; 0.674$ & 0.870 \\
\hline Cases stage III and IV & $60 / 87 / 18$ & 0.37 & 0.026 & $1,350(1,032-1,766) ; 0.029$ & 0.261 \\
\hline rs7739264 & $\mathrm{TT} / \mathrm{CT} / \mathrm{CC}$ & $\mathrm{C}-$ minor & & & \\
\hline Controls & $124 / 191 / 89$ & 0.46 & & & 0.636 \\
\hline Cases & $92 / 149 / 70$ & 0.46 & 0.770 & $1,033(0.837-1,273) ; 0.765$ & 0.808 \\
\hline Cases stage I and II & $42 / 62 / 37$ & 0.48 & 0.473 & $1,108(0.845-1,454) ; 0.458$ & 0.366 \\
\hline Cases stage III and IV & $47 / 84 / 32$ & 0.45 & 0.935 & $0.989(0.764-1,281) ; 0.934$ & 0.881 \\
\hline rs1519761 & AA / AG / GG & G-minor & & & \\
\hline Controls & $125 / 209 / 65$ & 0.42 & & & 0.357 \\
\hline Cases & $104 / 162 / 44$ & 0.40 & 0.394 & $0.915(0.739-1,132) ; 0.413$ & 0.319 \\
\hline Cases stage I and II & $42 / 84 / 14$ & 0.40 & 0.441 & $0.903(0.684-1,191) ; 0.469$ & 0.013 \\
\hline Cases stage III and IV & $59 / 76 / 28$ & 0.40 & 0.531 & $0.921(0.709-1,197) ; 0.539$ & 0.918 \\
\hline rs6542095 & $\mathrm{TT} / \mathrm{CT} / \mathrm{CC}$ & C-minor & & & \\
\hline Controls & $201 / 178 / 25$ & 0.28 & & & 0.212 \\
\hline Cases & $168 / 126 / 21$ & 0.27 & 0.501 & $0.925(0.732-1,169) ; 0.514$ & 0.922 \\
\hline Cases stage I and II & $76 / 53 / 13$ & 0.28 & 0.985 & $0.980(0.725-1,325) ; 0.897$ & 0.702 \\
\hline Cases stage III and IV & $87 / 71 / 8$ & 0.26 & 0.467 & $0.903(0.677-1,206) ; 0.490$ & 0.394 \\
\hline
\end{tabular}

RAF — risk allele frequency

endometriosis with severity stages I/II and III/IV (Tab. 4). The prevalence of the genotype and allele frequencies, $\mathrm{OR}$, and 95\% Cl calculated for the ten SNPs for both fertile healthy women and women with endometriosis stages I/II and III/IV are presented in Table 4. In patients with endometriosis with severity stages III/IV, for the rs 12700667 SNP, we found statistically significant $p$ values of the Cochran-Armitage trend test $\left(p_{\text {trend }}=0.036\right)$ and OR for the RAF of $1.394(95 \% \mathrm{Cl}=$ $=1.010-1.923 ; p=0.043)$. In infertile women with endometriosis stages III/IV, for rs4141819 SNP, we observed statistically significant $\mathrm{p}$ values of the Cochran-Armitage trend test $\left(p_{\text {trend }}=0.026\right)$ and OR for the RAF of $1.350(95 \% \mathrm{Cl}=1.032$ $-1.766 ; p=0.029)$. However, we did not find any association between rs12700667 and rs4141819 SNPs in women with endometriosis severity stages I/II. Moreover, rs12037376, rs7521902, rs13394619, rs10859871, rs1537377, rs7739264, rs1519761 and rs6542095 failed to display a significant association with infertile women with endometriosis in stages I/II and III/IV in additive inheritance models (Tab. 4).

\section{DISCUSSION}

Large twin studies revealed approximately $50 \%$ heritability of endometriosis [16]. Numerous investigations on various candidate genes have been carried out to study the genetic background of endometriosis; however, some studies did not replicate these results $[16,17]$. Previous efforts to study the genetic background of endometriosis suggest that it is a highly complex field $[5,16,17]$.

Previous replication studies and meta-analysis studies conducted on GWAS in European ancestry cohorts found ten genome-wide significant single nucleotide polymorphisms (SNPs) associated with advanced endometriosis in Caucasians [7-13,18]. These include rs12700667 on 7p15.2 near NFE2L3 (erythroid-derived 2-like 3), rs12037376 in WNT4 (wingless-type MMTV integration site family, member 4), rs7521902 on 1 p36.12 near WNT4, rs13394619 on 2p25.1 in GREB1 (growth regulation by oestrogen in breast cancer 1), rs10859871 on 12q22 near VEZT (vezatin, adherens junctions transmembrane protein), 
rs1537377 on 9p21.3 near CDKN2B-AS1 (cyclin-dependent kinase inhibitor 2B antisense RNA), rs4141819 on 2p14 near ETAA1 (ewing tumour-associated antigen 1), rs7739264 on 6p22.3 near ID4 (inhibitor of DNA binding 4, dominant negative helix-loop-helix protein), rs1519761 on 2q23.3 near RND3 (Rho family GTPase 3 gene) and rs6542095 on 2q13 near IL1A (interleukin 1A) (Tab. 1) [7-13,18].

In our study we found association of the rs 12700667 polymorphism with infertility in Polish women with advanced endometriosis. The GWAS study conducted by Painter_et al. 2011 demonstrated rs12700667 SNP association with advanced endometriosis in Australia and the UK cohort and was replicated in independent cohort from the United States [10]. The rs12700667 SNP is located $290.2 \mathrm{~kb}$ upstream of the nuclear factor NFE2L3. Recently, in a Chinese population, it was reported that rs 12700667 significantly increased the risk of ovarian endometriosis [19].

We also found contribution of the rs4141819 polymorphism to infertility in Polish women with advanced endometriosis. The GWAS study carried out by Nyholt et al. 2012 revealed in European and Japanese ancestry rs4141819 SNP as risk factor for advanced endometriosis [9]. The rs4141819SNP is situated $\sim 227.0 \mathrm{~kb}$ downstream of the ETAA1 gene that encodes a tumour-specific cell surface antigen in the Ewing family of tumours [20]. The rs4141819 SNP is also located in the intronic region of a long non-coding RNA (IncRNA), AC007422.1, which has an unknown biological function. The association of rs12700667 and rs4141819 SNPs should be repeated in other independent Polish cohorts to assess the possible diagnostic value of these polymorphism in the development of infertility in Polish women with endometriosis.

However, we did not observe an association between rs12037376, rs7521902, rs13394619, rs10859871, rs1537377, rs7739264, rs1519761 and rs6542095 SNPs with infertility in Polish women with advanced endometriosis.

The GWAS study conducted in endometriotic women with European ancestry found association with the intrononic rs12037376 SNP of WNT4 and rs7521902 SNP situated $\sim 21.3 \mathrm{~kb}$ downstream of WNT4 [8,9]. WNT4 is considered to be associated with the development of the female genital tract and steroidogenesis [21].

Both rs13394619 and rs10859871 are endometriosis susceptible SNPs, that have been identified by GWAS meta-analysis in Japanese and European populations [9]. The rs13394619 SNP is situated in the intron region between exon 9 and exon 10 in the GREB1 gene, which is involved in hormone-dependent breast cancer cell growth [22]. Elevated expression of GREB1 has been suggested to be involved in oestrogen-dependent growth in peritoneal endometriosis [23]. The rs10859871 SNP is located $\sim 15.3 \mathrm{~kb}$ downstream of the VEZT gene, which is a putative tumour suppressor gene encoding an adherens junction transmembrane protein [24]. The rs10859871 SNP was replicated in Italian Caucasian women with endometriosis [25]. Recently, Holdsworth-Carson et al. (2016) reported the association of the rs10859871 SNP with increased VEZT expression in the secretory phase of the menstrual cycle in endometrial glands of women with endometriosis [26].

In the Nyholt et al., (2012) study of European ancestry they found an association of rs 1537377 and rs7739264 SNPs with endometriosis, excluding cases with minimal or unknown severity [9]. The rs1537377 SNP is located $\sim 48 \mathrm{~kb}$ upstream of the CDKN2B-AS1 gene. This gene, which is at the 9p21.3. locus, was first demonstrated in GWAS of endometriosis in a Japanese population [11]. CDKN2B-AS1 regulates $C D K N 2 A, C D K N 2 B$ and $A R F$ expression, which are known as tumour suppressor genes [27-29]. CDKN2A inactivation has been observed in endometriosis and endometrial cancer via loss of heterozygosity and promoter hypermethylation $[30,31]$. The rs 7739264 SNP is situated $\sim 52.0 \mathrm{~kb}$ upstream of the ID4 gene and in the intronic region of IncRNA, RPI$-167 F 1.2$, with unknown function. Changes in ID4 expression is involved in ovarian and breast carcinogenesis [32, 33].

The GWAS study carried out by Albertsen et al. (2013) has identified rs1519761 SNP to be associated with endometriosis in a European cohort [8]. The rs 1519761 is located in the intergenic region $\sim 289 \mathrm{~kb}$ downstream of the RND3 gene (OMIM *602924),

The Sapkota et al. (2015) study on a population of European ancestry revealed an association of rs6542095 SNP with a genome-wide significance in patients with moderate-to-severe endometriosis [13]. The rs6542095 SNP is situated $\sim 2.3 \mathrm{~kb}$ downstream of the IL $1 A$ gene. This SNP may regulate the expression of other genes, which could support the evidence for a relationship between the pathogenesis of endometriosis and inflammatory responses [34].

\section{CONCLUSIONS}

In our studies we replicated the rs 12700667 and rs4141819 association of RAF with infertility in Polish women with advanced endometriosis. However, we did not replicate rs12037376, rs7521902, rs13394619, rs10859871, rs1537377, rs7739264, rs1519761 and rs6542095 SNPs in infertile women, neither with all stages of endometriosis nor advanced endometriosis. The frequency of genetic polymorphisms varies according to ethnic groups, which may have effect on the sample size to get statistical power of study. Our study attributes the small population and lack of sufficient power for replication. Therefore, this study should be replicated in other independent cohorts. 


\section{Acknowledgements}

This work was supported by grant no. 502-01-01124182-07474 from Poznań University of Medical Sciences. The technical assistance of Ms. Justyna Dąbrowska is gratefully acknowledged.

\section{REFERENCES}

1. Wilczyński M, Wiecka-Płusa $M$, Antosiak B, et al. Rectovaginal endometriosis--analysis of 160 cases. Ginekol Pol. 2015; 86(12): 896-901, indexed in Pubmed: 26995938.

2. Bulun SE. Endometriosis. N Engl J Med. 2009; 360(3): 268-279, doi: 10.1056/NEJMra0804690, indexed in Pubmed: 19144942.

3. Luca A, Nemescu D, Butnaru M, et al. Ovarian stimulation outcome in infertile women with endometriosis undergoing IVF. Ginekol Pol. 2016; 87(1): 37-41, doi: 10.17772/gp/60073, indexed in Pubmed: 27306467.

4. Davis AC, Goldberg JM. Extrapelvic Endometriosis. Semin Reprod Med. 2017; 35(1): 98-101, doi: 10.1055/s-0036-1597122, indexed in Pubmed: 27992931.

5. Borghese B, Zondervan KT, Abrao MS, et al. Recent insights on the genetics and epigenetics of endometriosis. Clin Genet. 2017; 91(2): 254-264, doi: 10.1111/cge.12897, indexed in Pubmed: 27753067.

6. Jurkiewicz-Przondziono J, Lemm M, Kwiatkowska-Pamuła A, et al. Influence of diet on the risk of developing endometriosis. Ginekol Pol. 2017; 88(2): 96-102, doi: 10.5603/GP.a2017.0017, indexed in Pubmed: 28326519.

7. Adachi S, Tajima A, Quan J, et al. Meta-analysis of genome-wide association scans for genetic susceptibility to endometriosis in Japanese population. J Hum Genet. 2010; 55(12): 816-821, doi: 10.1038/jhg.2010.118, indexed in Pubmed: 20844546.

8. Albertsen HM, Chettier R, Farrington P, et al. Genome-wide association study link novel loci to endometriosis. PLoS One. 2013; 8(3): e58257, doi: 10.1371/journal.pone.0058257, indexed in Pubmed: 23472165.

9. Nyholt DR, Low SK, Anderson CA, et al. Genome-wide association meta-analysis identifies new endometriosis risk loci. Nat Genet. 2012; 44(12): 1355-1359, doi: 10.1038/ng.2445, indexed in Pubmed: 23104006.

10. Painter JN, Anderson CA, Nyholt DR, et al. Genome-wide association study identifies a locus at 7p15.2 associated with endometriosis. Nat Genet. 2011;43(1):51-54, doi: 10.1038/ng.731, indexed in Pubmed: 21151130.

11. Uno $S$, Zembutsu $H$, Hirasawa $A$, et al. A genome-wide association study identifies genetic variants in the CDKN2BAS locus associated with endometriosis in Japanese. Nat Genet. 2010; 42(8): 707-710, doi: 10.1038/ng.612, indexed in Pubmed: 20601957.

12. Rahmioglu N, Nyholt DR, Morris AP, et al. Genetic variants underlying risk of endometriosis: insights from meta-analysis of eight genome-wide association and replication datasets. Hum Reprod Update. 2014; 20(5): 702-716, doi: 10.1093/humupd/dmu015, indexed in Pubmed: 24676469.

13. Sapkota Y, Fassbender A, Bowdler L, et al. Independent Replication and Meta-Analysis for Endometriosis Risk Loci. Twin Res Hum Genet. 2015; 18(5): 518-525, doi: 10.1017/thg.2015.61, indexed in Pubmed: 26337243.

14. Canis M, Donnez JG, Guzick DS, et al. Revised American Society for Reproductive Medicine classification of endometriosis: 1996. Fertil Steril. 1997; 67(5): 817-821, doi: 10.1016/s0015-0282(97)81391-x., indexed in Pubmed: 9130884

15. Szczepańska M, Wirstlein P, Skrzypczak J, et al. Polymorphic variants of CYP17 and CYP19A and risk of infertility in endometriosis. Acta Obstet Gynecol Scand. 2013; 92(10): 1188-1193, doi: 10.1111/aogs.12210, indexed in Pubmed: 23809139.

16. Saha R, Pettersson HJ, Svedberg $P$, et al. Heritability of endometriosis. Fertil Steril. 2015; 104(4): 947-952, doi: 10.1016/j.fertnstert.2015.06.035, indexed in Pubmed: 26209831.

17. Rahmioglu N, Montgomery GW, Zondervan KT. Genetics of endometriosis. Womens Health (Lond). 2015; 11(5): 577-586, doi: 10.2217/whe.15.41, indexed in Pubmed: 26441051.
18. Sapkota Y, Low SK, Attia J, et al. Association between endometriosis and the interleukin 1A (IL1A) locus. Hum Reprod. 2015; 30(1): 239-248, doi: 10.1093/humrep/deu267, indexed in Pubmed: 25336714.

19. LiY, Hao Na, Wang YX, et al. Association of Endometriosis-Associated Genetic Polymorphisms From Genome-Wide Association Studies With Ovarian Endometriosis in a Chinese Population. Reprod Sci. 2016 [Epub ahead of print], doi: 10.1177/1933719116650753, indexed in Pubmed: 27233752.

20. Borowski A, Dirksen U, Lixin $L$, et al. Structure and function of ETAA16: a novel cell surface antigen in Ewing's tumours. Cancer Immunol Immunother. 2006; 55(4): 363-374, doi: 10.1007/s00262-005-0017-6, indexed in Pubmed: 16003559.

21. Vainio $S$, Heikkilä $M$, Kispert $A$, et al. Female development in mammals is regulated by Wnt-4 signalling. Nature. 1999; 397(6718): 405-409, doi: 10.1038/17068, indexed in Pubmed: 9989404.

22. Rae JM, Johnson MD, Scheys JO, et al. GREB 1 is a critical regulator of hormone dependent breast cancer growth. Breast Cancer Res Treat. 2005; 92(2): 141-149, doi: 10.1007/s10549-005-1483-4, indexed in Pubmed: 15986123.

23. Pellegrini C, Gori I, Achtari C, et al. The expression of estrogen receptors as well as GREB1, c-MYC, and cyclin D1, estrogen-regulated genes implicated in proliferation, is increased in peritoneal endometriosis. Fertil Steril. 2012; 98(5): 1200-1208, doi: 10.1016/j.fertnstert.2012.06.056, indexed in Pubmed: 22884659.

24. Miao R, Guo X, Zhi Q, et al. VEZT, a novel putative tumor suppressor, suppresses the growth and tumorigenicity of gastric cancer. PLoS One. 2013; 8(9): e74409, doi: 10.1371/journal.pone.0074409, indexed in Pubmed: 24069310.

25. Pagliardini L, Gentilini D, Sanchez AM, et al. Replication and meta-analysis of previous genome-wide association studies confirm vezatin as the locus with the strongest evidence for association with endometriosis. Hum Reprod. 2015; 30(4): 987-993, doi: 10.1093/humrep/dev022, indexed in Pubmed: 25678572.

26. Holdsworth-Carson SJ, Fung JN, Luong HTT, et al. Endometrial vezatin and its association with endometriosis risk. Hum Reprod. 2016; 31(5): 999-1013, doi: 10.1093/humrep/dew047, indexed in Pubmed: 27005890.

27. Jarinova O, Stewart AFR, Roberts R, et al. Functional analysis of the chromosome 9p21.3 coronary artery disease risk locus. Arterioscler Thromb Vasc Biol. 2009; 29(10): 1671-1677, doi: 10.1161/ATVBAHA.109.189522, indexed in Pubmed: 19592466.

28. Liu Y, Sanoff HK, Cho H, et al. INK4/ARF transcript expression is associated with chromosome 9p21 variants linked to atherosclerosis. PLoS One. 2009; 4(4): e5027, doi: 10.1371/journal.pone.0005027, indexed in Pubmed: 19343170.

29. Pasmant $E$, Laurendeau I, Héron $D$, et al. Characterization of a germ-line deletion, including the entire INK4/ARF locus, in a melanoma-neural system tumor family: identification of ANRIL, an antisense noncoding RNA whose expression coclusters with ARF. Cancer Res. 2007; 67(8): 3963-3969, doi: 10.1158/0008-5472.CAN-06-2004, indexed in Pubmed: 17440112.

30. Goumenou AG, Arvanitis DA, Matalliotakis IM, et al. Loss of heterozygosity in adenomyosis on hMSH2, hMLH1, p16Ink4 and GALT loci. Int J Mol Med. 2000; 6(6): 667-671, indexed in Pubmed: 11078826.

31. Martini M, Ciccarone M, Garganese G, et al. Possible involvement of hMLH1, p16(INK4a) and PTEN in the malignant transformation of endometriosis. Int J Cancer. 2002; 102(4): 398-406, doi: 10.1002/ijc.10715, indexed in Pubmed: 12402310.

32. Ren $\mathrm{Y}$, Cheung HW, von Maltzhan $\mathrm{G}$, et al. Targeted tumor-penetrating siRNA nanocomplexes for credentialing the ovarian cancer oncogene ID4. Sci Transl Med. 2012; 4(147): 147ra112, doi: 10.1126/scitranslmed.3003778, indexed in Pubmed: 22896676.

33. Verschuur-Maes AHJ, de Bruin PC, van Diest PJ. Epigenetic progression of columnar cell lesions of the breast to invasive breast cancer. Breast Cancer Res Treat. 2012; 136(3): 705-715, doi: 10.1007/s10549-012-23014, indexed in Pubmed: 23104224.

34. Miller JE, Ahn SH, Monsanto SP, et al. Implications of immune dysfunction on endometriosis associated infertility. Oncotarget. 2017; 8(4): 71387147, doi: 10.18632/oncotarget.12577, indexed in Pubmed: 27740937. 